\title{
PHYTOCHEMICAL RESEARCH AND ANTI-INFLAMMATORY ACTIVITY OF THE DRY EXTRACTS FROM NORTHERN HIGHBUSH BLUEBERRY LEAVES
}

\author{
Oleksandr Stremoukhov, Oleh Koshovyi, Mykola Komisarenko, Igor Kireyev, Andriy \\ Gudzenko, Michal Korinek, Tsong-Long Hwang, Meng-Hua Chen, Olha Mykhailenko
}

\begin{abstract}
All over the world, non-steroidal anti-inflammatory drugs (NSAIDs) are taken annually by about three hundred million people and this figure is constantly increasing. At the same time, NSAIDs are also one of the most common causes of side effects of drug therapy. The development and implementation of new anti-inflammatory drugs, including those of plant origin, with minimal side effects is an urgent task of modern pharmaceutical science. Vaccinium corymbosum L. (family Ericaceae), which is gaining more and more popularity among berry crops and is successfully cultivated in Ukraine, is promising in this direction for research.

The aim: phytochemical analysis of dry extracts from blueberry leaves to establish the possibility of creating new drugs with anti-inflammatory activity.
\end{abstract}

Materials and methods. The objects of the study were dry extracts of northern highbush blueberry leaves. The content of amino acids and phenolic compounds was determined by HPLC and spectrophotometry. The prototypal activity was studied in vivo and in vitro.

Research results. 4 dry extracts were obtained from northern highbush blueberry leaves. In the extracts obtained by HPLC, 7 amino acids were identified, including 3 essential ones: arginine, histidine, and phenylalanine. As a result of the HPLC study, 7 phenolic compounds were identified in extracts from the leaves of northern highbush blueberry: 5 flavonoids - rutin, quercetin-3-O-glucoside, kaempferol-3-O-glucoside, quercetin and kaempferol and 2 hydroxycinnamic acids, chlorogenic and caffeic acid. For the first time, the anti-inflammatory effect of extracts from blueberry leaves was investigated. It was revealed that extract 1 at a dose of $50 \mathrm{mg} / \mathrm{kg}$ and extract 4 modified with arginine at a dose of $25 \mathrm{mg} / \mathrm{kg}$ have the highest anti-inflammatory activity.

Conclusions. The results of the conducted studies indicate that extracts from the leaves of northern highbush blueberry in terms of the content of biologically active substances are promising sources for the creation of new drugs and dietary supplements with anti-inflammatory activity

Keywords: northern highbush blueberry, dry extract, phenolic compounds, amino acid, anti-inflammatory activity

How to cite:

Stremoukhov, O., Koshovyi, O., Komisarenko, M., Kireyev, I., Gudzenko, A., Korinek, M., Hwang, T.-L., Chen, M.-H. Mykhailenko, O. (2021). Phytochemical research and anti-inflammatory activity of the dry extracts from northern highbush blueberry leaves. ScienceRise: Pharmaceutical Science, 2 (30), 40-48. doi: http://doi.org/10.15587/2519-4852.2021.230288

(C) The Author(s) 2021

This is an open access article under the Creative Commons CC BY license

\section{Introduction}

Inflammation is a typical pathological process that underlies many diseases, is widespread, is accompanied by severe clinical manifestations and is the cause of partial or complete disability of large groups. Worldwide, non-steroidal anti-inflammatory drugs (NSAIDs) are taken by about three hundred million people annually and this number is constantly increasing [1]. At the same time, NSAIDs are also one of the most common causes of side effects of drug therapy. In the United States, NSAIDs are the 15th most common cause of death. Thus, in the United States alone, about 16,500 patients die each year from NSAID gastropathies, and in the United Kingdom - about 2,000 [2, 3]. Development and introduction of new anti-inflammatory drugs, including herbal ones, with minimal side effects is an urgent task of modern pharmaceutical science.

Vaccinium corymbosum L. (Ericaceae family), which is gaining more and more popularity among berry crops and is successfully cultivated in Ukraine, is prom- ising in this direction for research. Northern highbush blueberry is a deciduous plant $[4,5]$. During the collection of fruits and pruning of bushes, a large volume of leaves remains, so the study of BAS of this raw material is relevant [6].

The main active ingredients of Northern highbush blueberry are phenols and their glycosides (hydroquinone, arbutin and methylarbutin) [7], hydroxycinnamic acids, coumarins, flavonoids (kaempferol, quercetin, astragalin, hyperoside, herbacetin, 8), lutecetin, tannins and their metabolites and terpenes ( $\alpha$-pinene and $\beta$ pinene) $[10,11]$. Such a rich composition of phenolic compounds creates the preconditions for the development of new raw materials from this raw material with anti-inflammatory activity.

The aim of the work was to conduct a phytochemical analysis of dry extracts from the leaves of Northern highbush blueberry to establish the possibility of creating new drugs with anti-inflammatory activity. 


\section{Planning (methodology) of research}

Given the previous experience of creating extracts from the leaves of plants of the family Ericaceae, it is planned to obtain extracts, modify them, investigate the phytochemical profile and anti-inflammatory activity to establish the possibility of using them as antiinflammatory agents (Fig. 1).

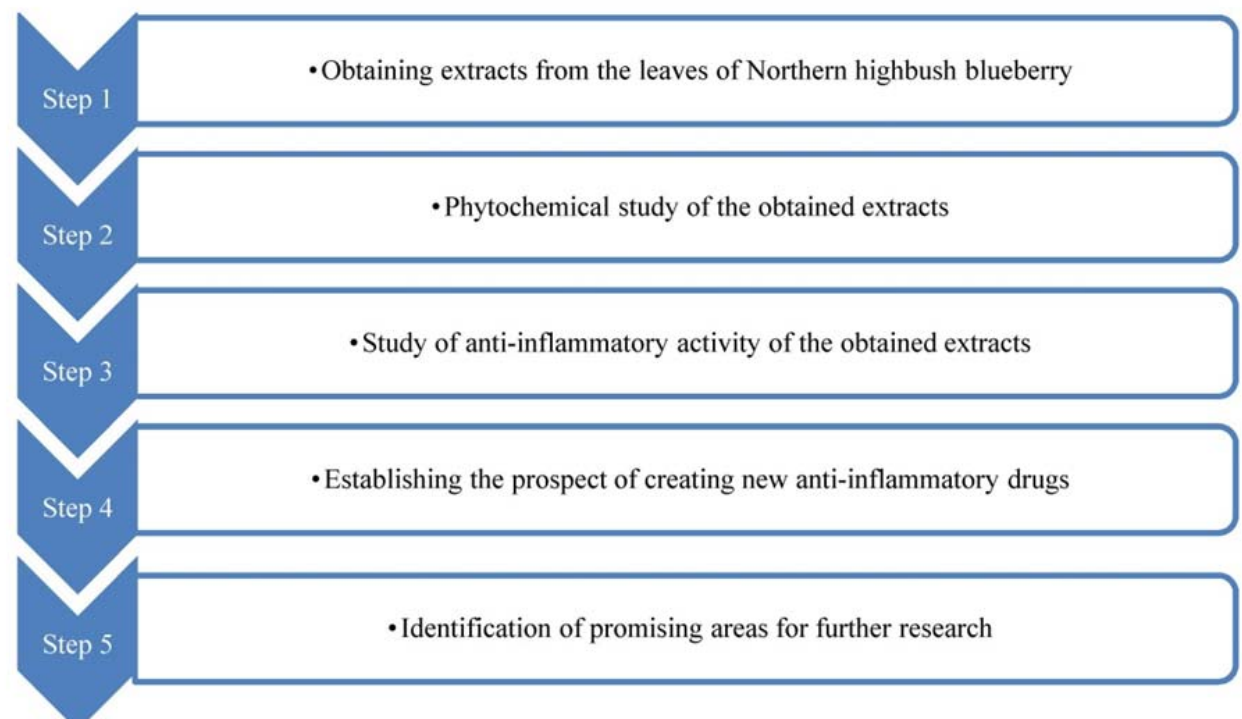

Fig. 1. Scheme of research of extracts from the leaves of Northern highbush blueberry

\section{Materials and methods}

\subsection{Plant material}

Plant raw material, $V$. corymbosum L. leaves, were collected in growing season, June-July, 2020, from Kharkov region, Ukraine області (GPS: 49²7`41.1 “ N, $\left.36^{\circ} 50^{\prime} 42.7^{\prime \prime} \mathrm{E}\right)$. Species identification was carried out by prof. Gontova T.M. at the Department of Botany, the National University of Pharmacy, Ukraine. Plant raw material was air-dried in darkness at room temperature. For chemical analysis, the raw material was ground to a particle size of 2-3 $\mathrm{mm}$.

\subsection{Obtaining extracts}

Four extracts were obtained from Northern highbush blueberry leaves as follows: $200.0 \mathrm{~g}$ of Northern highbush blueberry leaves, crushed to a particle size of 2-3 mm, were placed in a flask, filled with $1000.0 \mathrm{ml}$ of $50 \%$ ethanol solution, extracted overnight at room temperature. The extraction was repeated three times with new portions of the extractant of $600.0 \mathrm{ml}$. The resulting extracts were combined, settled and filtered. The filtrate was evaporated using a rotary vacuum evaporator "Heidolph 2 WBeco, Laborata 400 efficient" (Germany) to a dry extract (Extract 1).

Amino acids are able to form salts, conjugates, amides, etc. with other BAS (biologically active substances) extracts, while changing their bioavailability, solubility and pharmacodynamic profile $[12,13]$. Depending on the conditions of amino acid addition, different products can be formed, so we proposed three ways of introducing amino acids: mechanical mixing and adding to the solution of the extract with different acidifying agents (acetic and citric acid).

To $5 \mathrm{~g}$ of the obtained dry extract 1 was added arginine in three times the equimolar amount relative to the total amount of phenolic compounds, which was $2.61 \mathrm{~g}$.
The mixture was mixed in a mortar to a homogeneous mass (extract 2).

$5 \mathrm{~g}$ of the obtained dry extract 1 was dissolved in $50 \mathrm{ml}$ of $50 \%$ ethanol solution, $15 \%$ acetic acid solution was added to $\mathrm{pH} 4$. $2.61 \mathrm{~g}$ of arginine was added to the flask with the obtained solution, followed by refluxing in a water bath until complete dissolution and left to infuse for 24 hours. After that, the solution was evaporated to dryness using a rotary vacuum evaporator (extract 3 ).

$5 \mathrm{~g}$ of the obtained dry extract 1 was dissolved in $50 \mathrm{ml}$ of $50 \%$ ethanol solution, citric acid was added to $\mathrm{pH} 5$ with constant stirring in a water bath. $2.61 \mathrm{~g}$ of arginine was added to the flask with the resulting solution, followed by refluxing in a water bath until complete dissolution and left to infuse overnight. After that, the solution was evaporated to dryness using a rotary vacuum evaporator (extract 4). Subsequently, extracts 1-4 were used for analysis.

\subsection{Analysis of the chemical composition of ex-} tracts

\section{HPLC}

\subsubsection{Investigation of phenolic compounds by}

Separation of the sum of phenolic compounds was carried out by HPLC $[14,15]$ on a high-performance liquid chromatograph Agilent Technologies (model 1100), which is equipped with a flow-through vacuum degasser G1379A, a four-channel low-pressure gradient pump G13111A, an automatic injector G1313A, a column thermostat G13116A and a diode-matrix detector G1316A. A $2.1 \times 150 \mathrm{~mm}$ chromatographic column filled with an octadecylsilyl sorbent with a grain size of $3.5 \mu \mathrm{m}$ "ZORBAX-SB C-18" was used for analysis. The analysis was performed under the following conditions: thermostat temperature $-35^{\circ} \mathrm{C}$; the flow rate of the mobile phase $-0.25 \mathrm{ml} / \mathrm{min}$; as the mobile phase used solution A $(0.1 \%$ phosphoric acid, $180 \mu \mathrm{l} / 1$ triethyla- 
mine, $3 \mathrm{ml} / \mathrm{l}$ tetrahydrofuran in water) and solution $\mathrm{B}$ $(\mathrm{MeOH})$ in a ratio of 90:10 (first $8 \mathrm{~min}$ ), 70:30 (8 to 24 $\mathrm{min}$ ), and from $24 \mathrm{~min}$ used only solution B; the working pressure of the eluent is $240-300 \mathrm{kPa}$. The following detection parameters were set during the analysis: measurement scale -1.0 ; scan time $-0.5 \mathrm{~s}$; spectrum removal parameters - each peak 190-600 nm [14]. Sample preparation: 50.0 $\mathrm{mg}$ (exact portion) of the extract was weighed in a $5.0 \mathrm{ml}$ test tube and adjusted to the mark with methanol. After 30 min in an ultrasonic bath, the sample was insisted at room temperature for 3-4 hours, then the tube was again placed on an ultrasonic bath for $15 \mathrm{~min}$, then the solution was filtered through a Teflon filter with a pore size of $0.45 \mu \mathrm{m}$ in a vial for analysis. The sample volume is $2 \mu$ l. Identification of phenolic compounds was performed by the retention time of hydroxycinnamic acid and flavonoid standards and their spectral characteristics [16, 17].

\subsubsection{Determination of the quantitative content of phenolic compounds}

Total polyphenols. Quantitative determination of total polyphenols was carried out by spectrophotometry in terms of pyrogalol according to the pharmacopoeial method (SPhU 2.0) [18-20].

Total flavonoids. Determination of total flavonoids was carried out by absorption spectrophotometry in terms of rutine, which is present in the leaves in the predominant amount. (SPhU 2.0,) [19, 20, 22].

Hydroxycinnamic acids. Quantitative determination of hydroxycinnamic acids was carried out by the modified method of absorption spectrophotometry in terms of chlorogenic acid (SPhU 2.0) [19, 22, 23].

\section{by HPLC}

3.3.3. Investigation of amino acids compounds

Determination of amino acid content was performed using Agilent 1260 Infinity HPLC System (degasser, binary pump, autosampler; single-quadrupole mass spectrometer Agilent 6120 with electrospray ionization (ESI); OpenLAB CDS Software. Zorbax RX-SIL column $(1.8 \mu \mathrm{m}, 46 \mathrm{~mm} \times 50 \mathrm{~mm}$, Agilent $)$ with protective filter. Under the conditions of the HPLC study used a gradient mode using a buffer solution: $\mathrm{A}-\mathrm{H}_{2} \mathrm{O}$ ( $\mathrm{HCOOH} 0.1 \%$ ) and a solution of organic modifier: B $\mathrm{CH}_{3} \mathrm{CN}$ (HCOOH $0.1 \%$ ). The flow rate is $0.4 \mathrm{ml} / \mathrm{min}$. Injection volume was $10 \mu \mathrm{l}$. Column temperature $40^{\circ} \mathrm{C}$. MS detection conditions: ion source: API-ES; ion scan mode 50-300 m/z; mode of extraction of chromatograms by individual ions depending on molecular weight, EIS; positive polarity. The work used acetonitrile "HPLC Super gradient" (Avantor performance materials inc, Poland) and formic acid (pure, AppliChem $\mathrm{GmbH}$, Darmstadt). Highly purified water $\left(18 \mathrm{M} \Omega\right.$ at $\left.25^{\circ} \mathrm{C}\right)$ was prepared using the Direct Q $3 \mathrm{UV}$ water purification system (Millipore, Molsheim, France). Amino acids (QDA qualifications) - glycine, alanine, serine, valine, threonine, methionine, histidine, phenylalanine, arginine, tryptophan $[19,24,25]$. extracts

3.4. Study of anti-inflammatory activity of

3.4.1. In vivo study in a model of carrageenan edema

The study of anti-inflammatory activity of highbush blueberry extracts was conducted at the Clinicaldiagnostic center of NUPh under the guidance of prof. Kireev I. V. The experimental work was performed in the scope of simple pharmacological screening. Animals were standardized for physiological and biochemical parameters and were in vivarium in accordance with sanitary and hygienic standards on a standard diet. During the experiment with animals, they behaved in accordance with the International principles of the european convention for the protection of vertebrate animals used for experiments and other scientific purposes [26].

The study of anti-inflammatory activity of highbush blueberry extracts was carried out in accordance with the guidelines "Preclinical studies of drugs" [27]. The experiments were performed on male rats weighing 180-220 g, which were divided into 6 groups of 6 animals each. The first group - control, the sixth group - intact animals. To study the effect of the obtained blueberry extracts on the course of the exudative phase of inflammation, a model of rat paw edema caused by subplanar administration of a phlogogenic agent - carrageenan solution was used. The paw volume was measured before and every hour until the time of the greatest development of edema (4 hours). For 2 $\mathrm{h}$ and immediately after the introduction of the phlogogenic agent, the animals were injected intraperitoneally with blueberry extracts at doses of $15,25,50,75$ and $100 \mathrm{mg} / \mathrm{kg}$. The effect of blueberry extracts was evaluated on the ability to suppress swelling of the paws of rats. As a drug - a comparison with the known anti-inflammatory effect used diclofenac sodium.

\subsubsection{Assessment of anti-inflammatory activity} using in vitro assay

Blood was taken from healthy human donors using a protocol approved by the Chang Gung Memorial Hospital review board. Neutrophils were isolated according to the standard procedure described before [28]. The inhibition of superoxide anion generation was measured by the reduction of ferricytochrome $\mathrm{C}$ as previously described [29]. Elastase release representing the degranulation from azurophilic granules was evaluated as described before [30]. Experimental conditions have been described in detail earlier [31].

\subsection{Statistics}

Student's t-test was used to statistically test the hypothesis of the probability of differences between the indicators of different groups. Statistical processing of the results was done by calculating the arithmetic mean, the average error of the arithmetic value, the reliability of the differences between results by the methods of variation statistics (SPhU 2.0, Vol.1 - 5.3, 5.3.N1) using Statistica 6.0 program and Word Excel. The number of repetitions of experiments (n) equals 5 [19]. 


\section{Research results}

The obtained extracts are brownish-yellow powders with a characteristic specific odor. The yield of dry extract 1 from the leaves of blueberries was $27.35 \%$. Extract 2 was brownish-yellow in color, but sometimes had white patches of arginine, while extracts 3 and 4 were uniformly light brown in color.

Qualitative composition and quantitative content of free amino acids in blueberry leaf extracts were performed by HPLC (Table 1).

Table 1

Amino acid content (\%) in extracts of highbush blueberry leaves

\begin{tabular}{|c|c|c|c|c|}
\hline Amino acid & Extract 1 & Extract 2 & Extract 3 & Extract 4 \\
\hline Glycine & $1.02 \pm 0.03$ & $0.63 \pm 0.06$ & $0.67 \pm 0.06$ & $0.81 \pm 0.04$ \\
\hline Alanine & $0.66 \pm 0.03$ & $0.66 \pm 0.03$ & $0.66 \pm 0.03$ & $0.65 \pm 0.02$ \\
\hline Serine & $1.50 \pm 0.04$ & $0.98 \pm 0.07$ & $0.93 \pm 0.04$ & $0.95 \pm 0.06$ \\
\hline Valine & $0.53 \pm 0.04$ & $0.33 \pm 0.05$ & $0.35 \pm 0.02$ & $0.34 \pm 0.03$ \\
\hline Histidine & $0.22 \pm 0.01$ & $0.15 \pm 0.01$ & $0.15 \pm 0.02$ & $0.14 \pm 0.01$ \\
\hline Phenylalanine & $0.33 \pm 0.04$ & $0.23 \pm 0.02$ & $0.19 \pm 0.01$ & $0.21 \pm 0.03$ \\
\hline Arginine & $1.16 \pm 0.04$ & $35.09 \pm 1.18$ & $32.1 \pm 0.95$ & $31.82 \pm 0.76$ \\
\hline
\end{tabular}

Determination of the qualitative composition and quantitative content of phenolic compounds in the study objects was performed by HPLC (Table 2, Fig. 2).

Quantitative determination of the content of the main groups of phenolic compounds (total polyphenols, flavonoids and hydroxycinnamic acids) in extracts of blueberry leaves was performed by spectrophotometry by pharmacopoeial methods (Table 3).

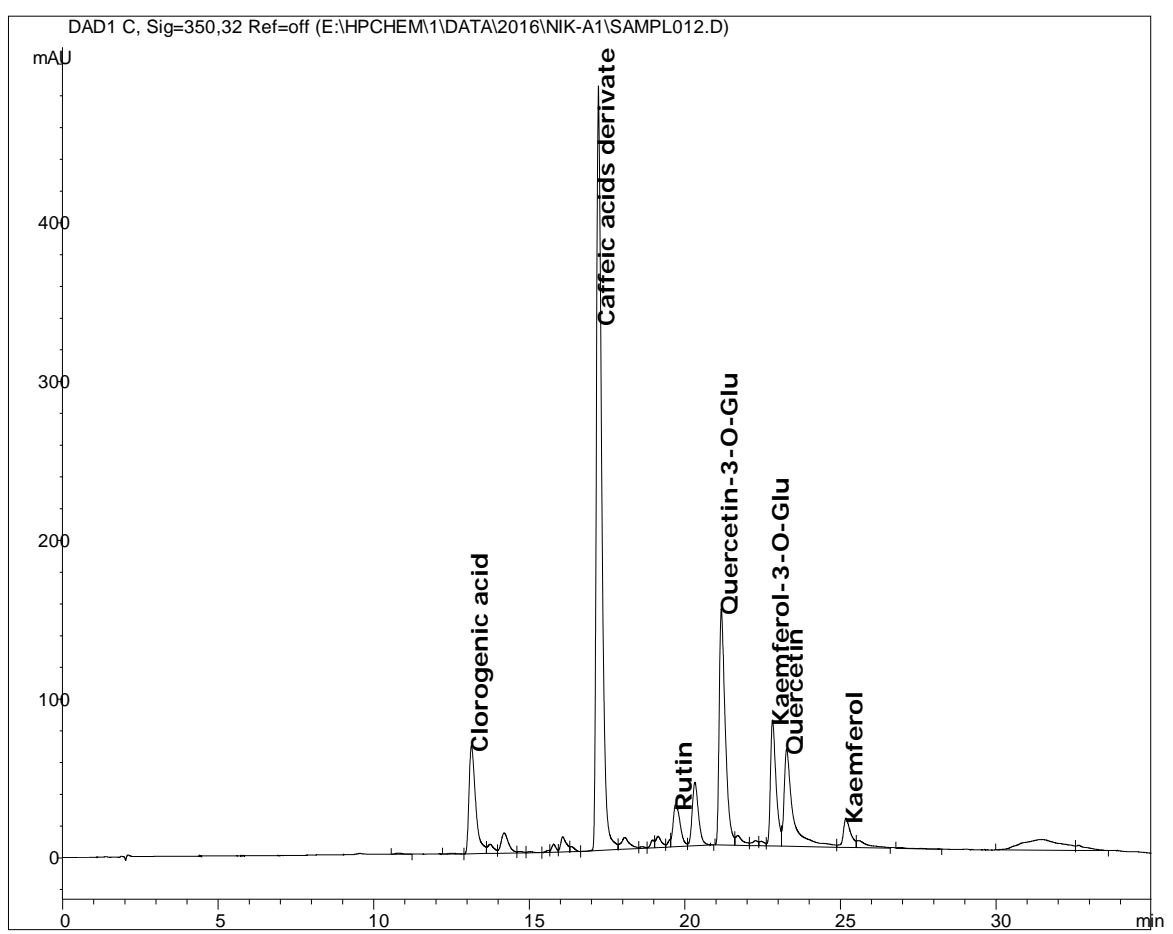

Fig. 2. Typical chromatogram of phenolic compounds of extract 1 from highbush blueberry leaves

Table 2

Quantitative content of phenolic compounds in highbush blueberry extracts

\begin{tabular}{|c|l|c|c|c|c|c|}
\hline \multirow{2}{*}{ No. Compound } & \multirow{2}{*}{ Retention time, min. } & \multicolumn{3}{|c|}{ Content in the extract, $\mathrm{mg} / 100 \mathrm{~g}$} \\
\cline { 4 - 7 } & & & 2 & 3 & 4 \\
\hline 1. & Chlorogenic acid & 13.14 & 1217.21 & 799.10 & 719,19 & 759,09 \\
\hline 2. & Caffeic acid & 17.22 & 3124.65 & 2051.33 & 1846,20 & 1948,63 \\
\hline 3. & Routine & 19.70 & 474.88 & 311.76 & 280,59 & 296,15 \\
\hline 4. & Quercetin-3-O-glucoside & 21.17 & 2293.65 & 1507.05 & 1356,34 & 1431,60 \\
\hline 5. & Kaempferol-3-O-glucoside & 22.82 & 1136.74 & 746.27 & 671,65 & 708,91 \\
\hline 6. & Quercetin & 23.27 & 888.60 & 583.37 & 525,03 & 554,16 \\
\hline 7. & Kaempferol & 25.18 & 206.74 & 135.73 & 122,15 & 128,93 \\
\hline Sum & & 9342,47 & 6134.61 & 5521.15 & 5827.48 \\
\hline
\end{tabular}


Quantitative content of phenolic compounds in extracts of highbush blueberry leaves $(\mathrm{M} \pm \mathrm{m}, \mathrm{n}=5)$

\begin{tabular}{|c|c|c|c|c|c|}
\hline \multirow{2}{*}{ BAS group } & \multirow{2}{*}{ The used method } & \multicolumn{4}{|c|}{ Quantitative content in the extract, $\%$} \\
\hline & & 1 & 2 & 3 & 4 \\
\hline $\begin{array}{l}\text { Derivatives of hy- } \\
\text { droxycinnamic acids }\end{array}$ & $\begin{array}{l}\text { Spectrophotometric method in terms of } \\
\text { chlorogenic acid }\end{array}$ & $2.92 \pm 0.12$ & $1.92 \pm 0.11$ & $1.9 \pm 0.12$ & $1.83 \pm 0.12$ \\
\hline Flavonoids & $\begin{array}{l}\text { Spectrophotometric method in terms of } \\
\text { routine }\end{array}$ & $3.03 \pm 0.11$ & $1.99 \pm 0.10$ & $1.97 \pm 0.11$ & $1.77 \pm 0.11$ \\
\hline Phenolic compounds & $\begin{array}{l}\text { Spectrophotometric method in terms of } \\
\text { pyrogalol }\end{array}$ & $18.42 \pm 0.97$ & $12.1 \pm 0.63$ & $11.97 \pm 0.62$ & $11.86 \pm 0.62$ \\
\hline
\end{tabular}

The obtained results of experimental studies of anti-inflammatory activity of blueberry extracts in the model of carrageenan edema of the hind limb in rats are given in Table 4. When studying extracts from highbush blueberry leaves in vitro on human blood neutrophils, only extracts 1 and 4 showed activity (Table 5).

Table 4

The effect of blueberry extracts on the development of inflammation of the hind limb in rats in a model of carrageenan edema

\begin{tabular}{|c|c|c|c|c|c|c|c|c|c|c|}
\hline \multirow{2}{*}{$\begin{array}{l}\text { Group of } \\
\text { animals }\end{array}$} & \multirow{2}{*}{$\begin{array}{l}\text { dose, } \\
\mathrm{mg} / \mathrm{kg}\end{array}$} & \multicolumn{5}{|c|}{ Limb volume, c.u. } & \multicolumn{4}{|c|}{ Antiexudative activity, $\%$} \\
\hline & & starting point & $1 \mathrm{~h}$ & $2 \mathrm{~h}$ & $3 \mathrm{~h}$ & $4 \mathrm{~h}$ & $1 \mathrm{~h}$ & $2 \mathrm{~h}$ & $3 \mathrm{~h}$ & $4 \mathrm{~h}$ \\
\hline $\begin{array}{c}\text { Control } \\
\text { pathology }\end{array}$ & & $42.5 \pm 1.47$ & $57.5 \pm 1.47$ & $57.5 \pm 1.47$ & $62.5 \pm 1.47$ & $59.5 \pm 1.47$ & & & & \\
\hline $\begin{array}{c}\text { Diclofenac } \\
\text { sodium }\end{array}$ & 8 & $36 \pm 0.98$ & $46 \pm 0.98$ & $41 \pm 0.98$ & $47 \pm 0.98$ & $37 \pm 0.98$ & 33 & 67 & 45 & 94 \\
\hline \multirow{5}{*}{ Extract 1} & 15 & $35.5 \pm 1.47$ & $45.5 \pm 4.42$ & $47.5 \pm 4.42$ & $46.5 \pm 4.42$ & $44 \pm 6.88$ & 33 & 20 & 45 & 50 \\
\hline & 25 & $36 \pm 2.95$ & $44.5 \pm 0.49$ & $45.5 \pm 1.47$ & $46.5 \pm 4.42$ & $48.5 \pm 5.41$ & 43 & 37 & 48 & 26 \\
\hline & 50 & $36.5 \pm 2.46$ & $43 \pm 2.95$ & $41.5 \pm 1.47$ & $41.5 \pm 1.47$ & $41 \pm 0.98$ & 57 & 67 & 75 & 74 \\
\hline & 75 & $33 \pm 0.98$ & $50.5 \pm 1.47$ & $50.5 \pm 4.42$ & $53.5 \pm 5.41$ & $48 \pm 2.95$ & 17 & 17 & 2 & 12 \\
\hline & 100 & $36 \pm 0.98$ & $49 \pm 4.91$ & $49.5 \pm 4.42$ & $50.5 \pm 0.49$ & $49.5 \pm 0.49$ & 13 & 10 & 28 & 21 \\
\hline \multirow{5}{*}{ Extract 2} & 15 & $37.5 \pm 3.44$ & $45.5 \pm 4.42$ & $44.5 \pm 5.41$ & $47 \pm 4.91$ & $46.5 \pm 5.41$ & 47 & 53 & 53 & 47 \\
\hline & 25 & $34 \pm 0.98$ & $45 \pm 4.91$ & $41.5 \pm 2.46$ & $44 \pm 1.97$ & $46 \pm 0.98$ & 27 & 50 & 50 & 29 \\
\hline & 50 & $33 \pm 0.98$ & $43 \pm 2.95$ & $41.5 \pm 1.47$ & $43.5 \pm 0.49$ & $43.5 \pm 2.46$ & 33 & 43 & 48 & 38 \\
\hline & 75 & $35.5 \pm 4.42$ & $44 \pm 0.98$ & $45 \pm 0.98$ & $47.5 \pm 2.46$ & $42 \pm 0.98$ & 43 & 37 & 40 & 62 \\
\hline & 100 & $36 \pm 0.98$ & $44.5 \pm 0.49$ & $46 \pm 0.98$ & $53 \pm 0.98$ & $46 \pm 0.98$ & 43 & 33 & 15 & 41 \\
\hline \multirow{5}{*}{ Extract 3} & 15 & $24.5 \pm 2.46$ & $36 \pm 0.98$ & $34 \pm 0.98$ & $30.5 \pm 1.47$ & $32 \pm 1.97$ & 23 & 37 & 70 & 56 \\
\hline & 25 & $26 \pm 0.98$ & $37.5 \pm 1.47$ & $35 \pm 2.95$ & $33 \pm 0.98$ & $34 \pm 1.97$ & 23 & 40 & 65 & 53 \\
\hline & 50 & $27.5 \pm 2.46$ & $39.5 \pm 0.49$ & $37 \pm 0.98$ & $37.5 \pm 0.49$ & $32.5 \pm 0.49$ & 20 & 37 & 50 & 71 \\
\hline & 75 & $28 \pm 0.98$ & $36 \pm 0.98$ & $33 \pm 0.98$ & $31.5 \pm 0.49$ & $30.5 \pm 1.47$ & 47 & 67 & 83 & 85 \\
\hline & 100 & $24 \pm 1.97$ & $39 \pm 1.97$ & $37 \pm 3.93$ & $35.5 \pm 0.49$ & $35 \pm 0.98$ & 0 & 13 & 43 & 35 \\
\hline \multirow{5}{*}{ Extract 4} & 15 & $29.5 \pm 3.44$ & $39 \pm 2.95$ & $37 \pm 2.95$ & $36 \pm 0.98$ & $33 \pm 1.97$ & 37 & 50 & 68 & 79 \\
\hline & 25 & $26 \pm 0.98$ & $35 \pm 0.98$ & $36.5 \pm 0.49$ & $32.5 \pm 1.47$ & $27.5 \pm 0.49$ & 40 & 30 & 68 & 91 \\
\hline & 50 & $25 \pm 0.98$ & $34.5 \pm 0.49$ & $36 \pm 0.98$ & $34 \pm 0.98$ & $32 \pm 0.98$ & 37 & 27 & 55 & 59 \\
\hline & 75 & $30 \pm 0.98$ & $40 \pm 2.95$ & $39 \pm 1.97$ & $38 \pm 0.98$ & $36 \pm 0.98$ & 33 & 40 & 60 & 65 \\
\hline & 100 & $25 \pm 1.97$ & $38 \pm 0.98$ & $38 \pm 0.98$ & $32.5 \pm 1.47$ & $29.5 \pm 1.47$ & 13 & 13 & 63 & 74 \\
\hline \multirow{5}{*}{ Arginine } & 15 & $42 \pm 1.97$ & $48 \pm 2.95$ & $60 \pm 9.83$ & $59.5 \pm 9.34$ & $60.5 \pm 10.32$ & $60 \%$ & $-20 \%$ & $13 \%$ & $-9 \%$ \\
\hline & 25 & $39.5 \pm 0.49$ & $44 \pm 1.97$ & $47 \pm 2.95$ & $49 \pm 1.97$ & $54.5 \pm 4.42$ & $70 \%$ & $50 \%$ & $53 \%$ & $12 \%$ \\
\hline & 50 & $36 \pm 0.98$ & $49.5 \pm 2.46$ & $55 \pm 0.98$ & $64 \pm 0.98$ & $62 \pm 0.98$ & $10 \%$ & $-27 \%$ & $-40 \%$ & $-53 \%$ \\
\hline & 75 & $41 \pm 0.98$ & $50.5 \pm 5.41$ & $51 \pm 0.98$ & $67.5 \pm 2.46$ & $63.5 \pm 3.44$ & $37 \%$ & $33 \%$ & $-33 \%$ & $-32 \%$ \\
\hline & 100 & $35 \pm 0.98$ & $46 \pm 0.98$ & $52.5 \pm 2.46$ & $57 \pm 1.97$ & $61.5 \pm 8.35$ & $27 \%$ & $-17 \%$ & $-10 \%$ & $-56 \%$ \\
\hline
\end{tabular}


Table 5

Effects of samples on superoxide anion generation and elastase release in FMLP/CB-induced human neutrophils

\begin{tabular}{|c|c|c|c|c|c|}
\hline \multirow{3}{*}{ Extract } & \multicolumn{3}{|c|}{ Superoxide anion } & \multicolumn{2}{c|}{ Elastase release } \\
\cline { 2 - 6 } & $\mathrm{IC}_{50}(\mu \mathrm{g} / \mathrm{ml})^{\mathrm{a}}$ & $\begin{array}{c}\mathrm{Inh} \% \\
(3 \mu \mathrm{g} / \mathrm{ml})\end{array}$ & $\begin{array}{c}\mathrm{Inh} \% \\
(10 \mu \mathrm{g} / \mathrm{ml})\end{array}$ & $\mathrm{IC}_{50}(\mu \mathrm{g} / \mathrm{ml})^{\mathrm{a}}$ & $\begin{array}{c}\text { Inh \% } \\
(10 \mu \mathrm{g} / \mathrm{ml})\end{array}$ \\
\hline 1 & $3.96 \pm 0.21$ & $44.08 \pm 1.07 * * *$ & $70.39 \pm 2.39 * * *$ & & $\mathrm{~b}$ \\
\hline 4 & & & $44.12 \pm 1.73 * * *$ & & $13.51 \pm 3.93 *$ \\
\hline
\end{tabular}

Note: percentage of inhibition (Inh \%) at $0.1-10 \mu \mathrm{g} / \mathrm{ml}$ concentration. Results are presented as mean \pm S.E.M. $(n=3) . * p<0.05$, ** $p<0.01$, *** $p<0.001$ compared with the control $(\mathrm{fMLP} / \mathrm{CB}) . \mathrm{BL2}$ and BL3 were insoluble in DMSO, water or $50 \%$ ethanol. ${ }^{a}$ Concentration necessary for $50 \%$ inhibition (IC50). ${ }^{b} B L 1(10 \mu \mathrm{g} / \mathrm{ml})$ induced elastase release in the presence of cytochalasin $B$ by $49.34 \pm 3.61 \%$ ***. Results are presented as mean \pm S.E.M. ( $n=3) . f M L F / C B$ induced cell responses were expressed as $100 \%$. *** $p<0.001$ compared with the basal (DMSO only)

\section{Discussion of research results}

The main active ingredients of highbush blueberry leaves, which determine their pharmacological action, are phenolic compounds. The solubility of these compounds significantly affects their bioavailability and the strength of the pharmacological effect. It was previously shown that the addition of various amino acids to plant plant extracts led to an increase in the pharmacological effect and the emergence of new activities $[12,13]$, so taking into account this experience, three ways to modify highbush blueberry extract with arginine: conventional mechanical displacement and modification in acidic alcohol solution. with two acidifying agents acetic and citric acid. The choice of arginine was due to the fact that the key factor regulating the tone of the vascular endothelium is the most important physiological vasodilator nitrogen monoxide. This mediator is formed from arginine under the action of $\mathrm{Ca}^{2+}-$ dependent enzyme NOsynthase (NOS) [34, 35]. 4 dry extracts with similar organoleptic characteristics were obtained.

In the obtained extracts from highbush blueberry leaves by HPLC revealed 7 amino acids (Table 1), including 3 essential: arginine, histidine and phenylalanine. The dominant amino acids in the original extract 1 were glycine, serine and arginine. Due to the fact that when obtaining extracts 2, 3 and 4 was added arginine in significant quantities, its content increased, but not proportionally: when mechanically mixed, this proportion was maintained, but when added to the solution, the amount of free arginine was lower than added, which can be explained by the formation of conjugates of arginine with other BAS extracts. The ratio of other amino acids also changed.

As a result of HPLC, in extracts of highbush blueberry leaves were found 7 phenolic compounds (Table 2): 5 flavonoids - rutin, quercetin-3-O-glucoside, kaempferol-3-O-glucoside, quercetin and kaempferol and 2 hydroxycinnamic chlorogenic acid and caffeic acid. Among hydroxycinnamic acids, caffeic acid was dominant, the content of which was 2.6 times higher than chlorogenic acid, among flavonoids - quercetin-3-Dglucoside and kaempferol-3-D-glucoside.

In the obtained extracts from highbush blueberry leaves, the quantitative content of the main BAS groups was determined by spectrophotometry according to $\mathrm{SPhU}$ methods (Table 3). Because spectrophotometric methods of analysis are more accessible, easy to perform and easy to reproduce and are more convenient and appropriate in the development of methods for standardization of extracts. The results of the analysis showed the same trend as HPLC analysis of the content of the main groups of BAS in the obtained extracts and will be used in the development of regulatory documentation for extracts. The values of spectrophotometric studies differ from HPLC analysis, which can be explained by the lower specificity of the spectrophotometric method and incomplete interpretation of substances in HPLC analysis.

Alteration is the first phase of the inflammatory process, triggers the entire cascade of inflammation, causing destructive changes in the affected tissue [36]. That is why the suppression of inflammation at the stage of its initiation is an important component of the success of anti-inflammatory therapy. The carrageenan edema model is one of the pharmacological models for assessing the anti-inflammatory activity of substances and drugs. This model in rats was used in pharmacological studies [26].

For the first time the anti-inflammatory effect of extracts from the leaves of blueberry was studied (Table 4). Extract 1 at a dose of $50 \mathrm{mg} / \mathrm{kg}$ and extract 4 modified with arginine at a dose of $25 \mathrm{mg} / \mathrm{kg}$ were found to have the highest anti-inflammatory activity. The effect of arginine on alteration was insignificant and, conversely, at a dose of $50 \mathrm{mg} / \mathrm{kg}$ and $100 \mathrm{mg} / \mathrm{kg}$ led to an increase in edema, while extracts from the leaves of blueberry had an anti-inflammatory effect. In the composition of the extract 4 available arginine, which was added in the preparation, taking into account this, in an effective dose of $25 \mathrm{mg} / \mathrm{kg}$, the content of BAS from the leaves of blueberries is only $16.7 \mathrm{mg} / \mathrm{kg}$, while without the addition of arginine, these BAS are effective at a dose of $50 \mathrm{mg} / \mathrm{kg}$, indicating potentiation of the action of phenolic compounds of Northern highbush blueberry arginine. This dose $(16.7 \mathrm{mg} / \mathrm{kg})$ can relieve inflammation at the level of the comparison drug diclofenac at a dose of $8 \mathrm{mg} / \mathrm{kg}$. Given the side effects of diclofenac sodium on the human body, we consider the use of modified extract 4 of the leaves of Northern highbush blueberry to create a new drug.

Anti-inflammatory activity of blueberry extracts against superoxide anion generation and elastase release in human neutrophils is shown in Table 5.

The major function of neutrophils include respiratory burst, degranulation and NETs formation serve as a first line of defense against pathogens and are important processes in the maintenance of human health. However, these processes need to be precisely regulated. Superoxide is a major radical produced by neutrophils while elastase belongs to major components of azurophilic granules [34] and their uncontrolled amount contributes to several acute and chronic diseases, including sepsis, ARDS, lung injury, arthritis or psoriasis [36]. These 
markers of neutrophilic inflammation were shown to be affected by several plant extracts [31].

Blueberry extracts were evaluated in human neutrophils against superoxide anion generation and elastase release triggered by fMLF in CB-primed human neutrophils. According to the results the extracts of blueberry BL1 had a profound effect on superoxide anion generation with IC50 $3.96 \mu \mathrm{g} / \mathrm{ml}$ (Table 5). Interestingly, the extracts of blueberry BL1 showed enhancing effects on elastase release by human neutrophils and thus may have immune-promoting effects related to the process of degranulation. BL4 exerted inhibitory effects on elastase release $(44 \%$ at $10 \mu \mathrm{g} / \mathrm{ml})$. Samples BL2 and BL3 were not tested due to low solubility in DMSO or water.

Study limitations. The amount of standard substances was limited during the study of plant raw materials by HPLC, so not all compounds of phenolic nature could be identified in the studied extracts. Only one model of inflammation was used in the study, which limits the ability to determine the mechanism of antiinflammatory activity.

Prospects for further research. The obtained results indicate the possibility of developing drugs based on the leaves of V.corymbosum. The results of research can be further used to develop methods of quality control of raw materials and drugs, developed basic schemes for obtaining extracts can be the basis for the development of technology for obtaining substances in industrial conditions. According to the results of phytochemical studies, it was found that extracts from the leaves of $V$. corymbosum are promising for the development of drugs with anti-inflammatory activity.

\section{Conclusions}

From the leaves of highbush blueberry were obtained dry extracts, modified by adding argin in various ways. 7 amino acids and 7 phenolic compounds were found in the obtained extracts: 5 flavonoids - rutin, quercetin-3-O-glucoside, kaempferol-3-O-glucoside, quercetin and kaempferol and 2 hydroxycinnamic acids chlorogenic and caffeic acids.

For the first time, the anti-inflammatory effect of highbush blueberry leaves extracts was studied in vivo and in vitro. The extract obtained with $50 \%$ ethanol solution at a dose of $50 \mathrm{mg} / \mathrm{kg}$ and the extract modified with arginine with the addition of citric acid at a dose of $25 \mathrm{mg} / \mathrm{kg}$ were found to have the greatest antiinflammatory activity.

The results of phytochemical and pharmacological studies indicate that extracts of highbush blueberry leaves in terms of BAS are promising sources for the development of new drugs and dietary supplements with anti-inflammatory activity.

\section{Conflict of interests}

The authors declare that they have no conflicts of interest.

\section{Funding}

The research was funded by the Ministry of Health Care of Ukraine at the expense of the State Budget in the framework \# 2301020 "Scientific and scientifictechnical activity in the field of health protection" on the topic "Modern approaches to the creation of new medicines for a correction of metabolic syndrome".

\section{References}

1. Green, G. A. (2001). Understanding NSAIDs: From aspirin to COX-2. Clinical Cornerstone, 3 (5), 50-59. doi: http://doi.org/10.1016/s1098-3597(01)90069-9

2. Gislason, G. H., Rasmussen, J. N., Abildstrom, S. Z., Schramm, T. K., Hansen, M. L., Fosbøl, E. L. et. al. (2009). Increased Mortality and Cardiovascular Morbidity Associated With Use of Nonsteroidal Anti-inflammatory Drugs in Chronic Heart Failure. Archives of Internal Medicine, 169 (2), 141-149. doi: http://doi.org/10.1001/archinternmed.2008.525

3. Marcus, M. B. (2011). New study links pain relievers to erectile dysfunction. USA Today.

4. Export-oriented blueberry cultivation (2020). Available at: https://inventure.com.ua/investments/vyrashivanie-golubiki

5. Strik, B. C., Finn, C. E., Moore, P. P. (2014). Blueberry cultivars for the Pacific Northwest. PNW, 656, 1-13.

6. Vaughan, J. G., Geissler, C. A. (2001). Rorsliny jadalne. Pryszy gnski i Spyłka. Warszawa

7. Müller, D., Schantz, M., Richling, E. (2012). High Performance Liquid Chromatography Analysis of Anthocyanins in Bilberries (Vaccinium myrtillus L.), Blueberries (Vaccinium corymbosum L.), and Corresponding Juices. Journal of Food Science, 77 (4), C340-C345. doi: http://doi.org/10.1111/j.1750-3841.2011.02605.x

8. Liu, B., Hu, T., Yan, W. (2020). Authentication of the Bilberry Extracts by an HPLC Fingerprint Method Combining Reference Standard Extracts. Molecules, 25 (11), 2514. doi: http://doi.org/10.3390/molecules25112514

9. Ștefănescu (Braic), R., Imre, S., Eșianu, S., Laczko-Zold, E., Dogaru, T. M. (2019). Vaccinium corymbosum leaves, a potential source of polyphenolic compounds. Romanian Biotechnological Letters, 24 (5), 755-760. doi: http://doi.org/10.25083/ $\mathrm{rb1} / 24.5 / 755.760$

10. Wang, L.-J., Wu, J., Wang, H.-X., Li, S.-S., Zheng, X.-C., Du, H. et. al. (2015). Composition of phenolic compounds and antioxidant activity in the leaves of blueberry cultivars. Journal of Functional Foods, 16, 295-304. doi: http://doi.org/10.1016/ j.jff.2015.04.027

11. Becker Pertuzatti, P., Teixeira Barcia, M., Gómez-Alonso, S., Teixeira Godoy, H., Hermosin-Gutierrez, I. (2021). Phenolics profiling by HPLC-DAD-ESI-MSn aided by principal component analysis to classify Rabbiteye and Highbush blueberries. Food Chemistry, 340, 127958. doi: http://doi.org/10.1016/j.foodchem.2020.127958

12. Koshovyi, O., Raal, A., Kireyev, I., Tryshchuk, N., Ilina, T., Romanenko, Y. et. al. (2021). Phytochemical and Psychotropic Research of Motherwort (Leonurus cardiaca L.) Modified Dry Extracts. Plants, 10 (2), 230. doi: http://doi.org/10.3390/plants10020230

13. Chaika, N., Koshovyi, O., Ain, R., Kireyev, I., Zupanets, A., Odyntsova, V. (2020). Phytochemical profile and pharmacological activity of the dry extract from Arctostaphylos uva-ursi leaves modified with phenylalanine. ScienceRise: Pharmaceutical Science, 6 (28), 74-84. doi: http://doi.org/10.15587/2519-4852.2020.222511

14. Krivoruchko, E., Markin, A., Samoilova, V., Ilina, T., Koshovyi, O. (2018). Research in the chemical composition of the bark of sorbus aucuparia. Ceska a Slovenska Farmacie, 67 (3), 113-115. 
15. De Brum, T., Zadra, M., Piana, M., Boligon, A., Fröhlich, J., de Freitas, R. et. al. (2013). HPLC Analysis of Phenolics Compounds and Antioxidant Capacity of Leaves of Vitex megapotamica (Sprengel) Moldenke. Molecules, 18 (7), 8342-8357. doi: http://doi.org/10.3390/molecules18078342

16. Koshovyi, O., Raal, A., Kovaleva, A., Myha, M., Ilina, T., Borodina, N., Komissarenko, A. (2020). The phytochemical and chemotaxonomic study of Salvia spp. growing in Ukraine. Journal of Applied Biology \& Biotechnology, 8 (3), 29-36. doi: http://doi.org/10.7324/jabb.2020.80306

17. Kyslychenko, V., Karpiuk, U., Diakonova, I., Abu-Darwish, M. S. (2010). Phenolic compounds and terpenes in the green parts of glycine hispidaю Advances in Environmental Biology, 4 (3), 490-494

18. Starchenko, G., Hrytsyk, A., Raal, A., Koshovyi, O. (2020). Phytochemical Profile and Pharmacological Activities of Water and Hydroethanolic Dry Extracts of Calluna vulgaris (L.) Hull. Herb. Plants, 9 (6), 751. doi: http://doi.org/10.3390/plants9060751 tsentr», 620

19. Derzhavna Farmakopeia Ukrainy (2008). Kharkiv: Derzhavne pidpryiemstvo «Naukovo-ekspertnyi farmakopeinyi

20. Hlushchenko, A. (2014). Quantitative determination of polyphenols in extracts of Salsola collina 1. Zbirnyk naukovykh prats spivrobitnykiv NMAPO im. P. L. Shupyka, 23 (4), 240-245.

21. Shinkovenko, I. L., Kashpur, N. V., Ilyina, T. V., Kovalyova, A. M., Goryacha, O. V., Koshovyi, O. M. et. al. (2018). The immunomodulatory activity of the extracts and complexes of biologically active compounds of Galium verum L. herb. Ceska a Slovenska Farmacie, 67 (1), 25-29.

22. Kislichenko, V. S., Burlaka, I. S., Karpyuk, U. V. (2013). Flavonoids from the Aerial Part of Calamagrostis epigeios. Chemistry of Natural Compounds, 49 (1), 133-134. doi: http://doi.org/10.1007/s10600-013-0532-1

23. Koshovyi, O. N., Vovk, G. V., Akhmedov, E. Yu., Komissarenko, A. N. (2015). The study of the chemical composition and pharmacological activity of Salvia officinalis leaves extracts getting by complex processing. Azerbaijan Pharmaceutical and Pharmacotherapy Journal, 15 (1), 30-34.

24. Karpyuk, U. V., Kislichenko, V. S., Gur'eva, I. G. (2015). HPLC Determination of Free and Bound Amino Acids in Bryonia alba. Chemistry of Natural Compounds, 51 (2), 399-400. doi: http://doi.org/10.1007/s10600-015-1298-4

25. Koshevoi, O. N. (2011). Amino-acid and monosaccharide compositions of Salvia officinalis leaves. Chemistry of Natural Compounds, 47 (3), 492-493. doi: http://doi.org/10.1007/s10600-011-9976-3

26. European Convention for the Protection of Vertebrate Animals (1986). Strasbourg. Available at: https://zakon.rada.gov.ua/laws/show/994_137\#Text

27. Stefanov, O. V. (Ed.) (2001). Preclinical studies of drugs. Kyiv, 527.

28. Boyum, A. (1968). Isolation of mononuclear cells and granulocytes from human blood. Isolation of monuclear cells by one centrifugation, and of granulocytes by combining centrifugation and sedimentation at $1 \mathrm{~g}$. Scandinavian Journal of Clinical and Laboratory Investigation, 97, 77-89.

29. Yang, S.-C., Chung, P.-J., Ho, C.-M., Kuo, C.-Y., Hung, M.-F., Huang, Y.-T. et. al. (2013). Propofol Inhibits Superoxide Production, Elastase Release, and Chemotaxis in Formyl Peptide-Activated Human Neutrophils by Blocking Formyl Peptide Receptor 1. The Journal of Immunology, 190 (12), 6511-6519. doi: http://doi.org/10.4049/jimmunol.1202215

30. Hwang, T.-L., Su, Y.-C., Chang, H.-L., Leu, Y.-L., Chung, P.-J., Kuo, L.-M., Chang, Y.-J. (2009). Suppression of superoxide anion and elastase release by C18 unsaturated fatty acids in human neutrophils. Journal of Lipid Research, 50 (7), $1395-1408$. doi: http://doi.org/10.1194/jlr.m800574-jlr200

31. Mykhailenko, O., Korinek, M., Ivanauskas, L., Bezruk, I., Myhal, A., Petrikaite, V. et. al. (2020). Qualitative and Quantitative Analysis of Ukrainian Iris Species: A Fresh Look on Their Antioxidant Content and Biological Activities. Molecules, 25 (19), 4588-4612. doi: http://doi.org/10.3390/molecules25194588

32. Zagayko, A. L., Voronina, L. M., Strelchenko, K. V. (2007). Metabolic Syndrom: Mechanisms of Development and Prospects for Antioxidant Therapy. Kharkiv: Golden Pages, 216.

33. Metabolic syndrome. National Heart, Lung, and Blood Institute. Available at: https://www.nhlbi.nih.gov/healthtopics/metabolic-syndrome Last accessed: 10.02.2019

34. Gregory, J. W. (2019). Prevention of Obesity and Metabolic Syndrome in Children. Frontiers in Endocrinology, 10, 669. doi: http://doi.org/10.3389/fendo.2019.00669

35. Chiang, C.-C., Cheng, W.-J., Korinek, M., Lin, C.-Y., Hwang, T.-L. (2019). Neutrophils in Psoriasis. Frontiers in Immunology, 10. doi: http://doi.org/10.3389/fimmu.2019.02376

36. Chiang, C.-C., Korinek, M., Cheng, W.-J., Hwang, T.-L. (2020). Targeting Neutrophils to Treat Acute Respiratory Distress Syndrome in Coronavirus Disease. Frontiers in Pharmacology, 11. doi: http://doi.org/10.3389/fphar.2020.572009

Received date 02.03.2021

Accepted date 19.04.2021

Published date 30.04.2021

Oleksandr Stremoukhov, Postgraduate Student, Department of Pharmacognosy, National University of Pharmacy, Pushkinska str., 53, Kharkiv, Ukraine, 61002

E-mail: stremoukhov_alexander@ukr.net

Oleh Koshovyi, Doctor of Pharmaceutical Sciences, Professor, Head of Department, Department of Pharmacognosy, National University of Pharmacy, Pushkinska str., 53, Kharkiv, Ukraine, 61002

E-mail: oleh.koshovyi@gmail.com

Mykola Komisarenko, PhD, Assistant, Department of Pharmacognosy, National University of Pharmacy, Pushkinska str., 53, Kharkiv, Ukraine, 61002

E-mail: a0503012358@gmail.com 
Igor Kireyev, MD, Professor, Director, Educational and Scientific Institute of Applied Pharmacy, National University of Pharmacy, Pushkinska str., 53, Kharkiv, Ukraine, 61002

E-mail: ivkireev1026@gmail.com

Andriy Gudzenko, Doctor of Pharmaceutical Sciences, Head of Department, Department of Chemistry, Private Higher Educational Establishment «Kyiv Medical University», Boyspilska str., 2, Kyiv, Ukraine, 02099 E-mail: ganvi75@gmail.com

Michal Korinek, PhD, Graduate Institute of Natural Products, College of Pharmacy, Department of Biotechnology, College of Life Science, Kaohsiung Medical University, No. 100, Shiquan 1st Road, Sanmin District, Kaohsiung City, Taiwan 80708, Graduate Institute of Natural Products, College of Medicine, Chang Gung University, No. 259, Wenhua 1st Road, Guishan District, Taoyuan City, Taiwan, 33302

E-mail: mickorinek@hotmail.com

Tsong-Long Hwang, Professor, Graduate Institute of Natural Products, College of Medicine, Chang Gung University, No. 259, Wenhua 1st Road, Guishan District, Taoyuan City, Taiwan, 33302, Research Center for Chinese Herbal Medicine, Research Center for Food and Cosmetic Safety, Institute of Health Industry Technology, College of Human Ecology, Chang Gung University of Science and Technology, No. 261, Wenhua 1st Road, Guishan District, Taoyuan City, Taiwan, 33303, Department of Anesthesiology, Chang Gung Memorial Hospital, No. 5, Fuxing Street, Guishan District, Taoyuan City, Taiwan, 33305

E-mail: htl@mail.cgu.edu.tw

Meng-Hua Chen, PhD, Graduate Institute of Natural Products, College of Medicine, Chang Gung University, No. 259, Wenhua 1st Road, Guishan District, Taoyuan City, Taiwan, 33302

E-mail: menghua0418@gmail.com

Olha Mykhailenko, PhD, Associate Professor, Department of Pharmaceutical Chemistry, National University of Pharmacy, Pushkinska str, 53, Kharkiv, Ukraine, 61002

E-mail: zolya85@gmail.com 